\title{
LASER WELDING AND ITS IMPLEMENTATION IN THE ASSEMBLY OF BATTERY PACKS IN AVIATION
}

by

Gábor Horváth, Andor Körmöczi, Tamás Szörényi and Zsolt Geretovszky

from the

Department of Optics and Quantum Electronics, University of Szeged, H-6720 Szeged, Dóm tér 9, Hungary

appeared in the

International Journal of Sustainable Aviation 6 (1) pp. 51-65 (2020)

and may be found at 


\section{LASER WELDING AND ITS IMPLEMENTATION IN THE ASSEMBLY OF BATTERY PACKS IN AVIATION}

Gábor Horváth, Andor Körmöczi, Tamás Szörényi and Zsolt Geretovszky

Department of Optics and Quantum Electronics, University of Szeged, H-6720 Szeged, Dóm tér 9, Hungary

\section{SUMMARY}

Following an overview of conventional bonding techniques used for the assembly of battery packs of modern hybrid vehicles special attention will be paid to laser keyhole welding. The unique challenges of aviatic applications, especially joining large number of batteries in a highly reproducible manner are pinpointed. The effect of contact area on the electrical and mechanical properties of laser welded joints is investigated on a DC01 steel model structure. The results are also discussed in terms of laser scanning speed. In the optimal process parameter range joints exhibiting electrical and mechanical properties appealing for assembling hybrid aircraft battery packs can be produced with high reproducibility.

Keywords: electric and hybrid aircraft, battery assembly, laser welding

\section{INTRODUCTION}

In today's fast developing world, environmentally friendly solutions are getting more and more into spotlight with the main reason being to reduce the damage inflicted on nature. As a result, more and more vehicles are equipped with hybrid or full electric drive systems instead of conventional combustion engines alone. (Ekici et al., 2020; Karakoc et al., 2019) These changes are most obvious in the automotive industry. Though the implementation is considerably slower, this trend is also present in aviation. The main bottleneck behind this evolution is the limited performance of the currently available batteries (as almost exclusively specific cylindrical $\mathrm{Li}$-ion cells have energy densities above 200 $\mathrm{Wh} / \mathrm{kg}$ ) and the uniquely stringent safety regulations of the aviation industry (failure rate of $10^{-7}$ ). Due to this, currently hybrid drive systems are sustainable in aviation, with the full electric systems being used only for very small or experimental vehicles with very limited flight time (less than an hour) and weight carrying capacity (few hundred kilograms) (Gál et al., 2017). As an example, the VUT 051 RAY is a working full electric aeroplane. In this vehicle 3060 Li-ion cells (Panasonic NCR18650A) are installed in 30 separate battery packs connected in series. The nominal parameters of the battery assembly are $324 \mathrm{~V}$ with $204 \mathrm{~A}$ maximal current accompanied by $102 \mathrm{Ah}$ charge. The power of the electric motor is $52 \mathrm{~kW}$ and the plane has a total weight of $230 \mathrm{~kg}$. Therefore, the batteries must have at least $227 \mathrm{Wh} / \mathrm{kg}$ energy density, which limits the applicable cell types greatly and leaves little room for additional weight carrying capability (Cipin et al., 2014). As mentioned, in the full electric models the power is solely supplied from a large capacity battery pack consisting of several small capacity cells connected in parallel and/or series. These battery packs are produced using a multi-level construction scheme that involves different types of bonding methods. (Figure 1)

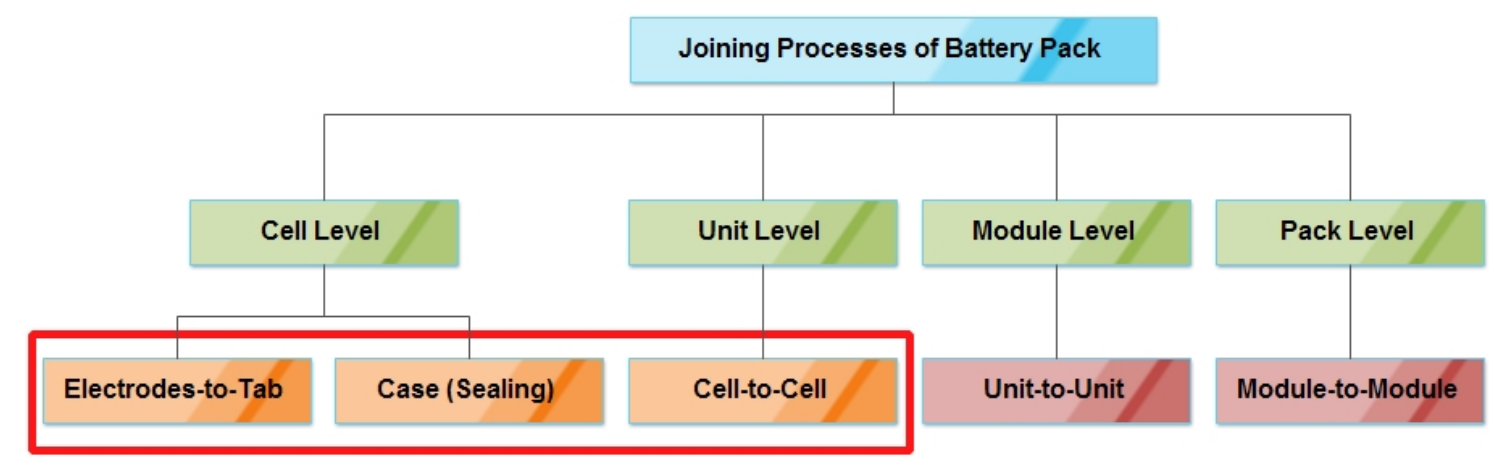


In general, mechanical joining (screws, rivets) are used at the higher levels of the construction process, mainly to preserve the modularity of the assembly. On the lower levels however (where numerous cells have to be joined) -the framed segment of Figure 1 -some form of a more refined permanent joining method (welding, brazing, etc.) is used in order to reduce the weight of the pack and to minimize the electrical loss at the connection points (Shawn et al., 2010).

In automobile battery assembly welding or wire bonding processes are most commonly used for low level joining. Welding is a technique for joining metals or certain plastics by fusing the material of the parts to be joined in liquid phase to form a permanent bond. It is therefore different from other permanent joining processes such as brazing where the base material does not melt (Ready, 2001; Ferjutz et al., 1993). Welding can be achieved by a variety of heat sources, each representing a different welding technique. (Table 1) For solving battery joining problems though, delicate welding system design and precise calculations are required in order to find the optimal process parameter windows in each individual application. Ultrasonic and especially laser welding are best suited for solving battery joining problems (Brand et al., 2015; Mehlmanna et al., 2014; Ferjutz et al., 1993).

\begin{tabular}{|c|c|c|c|c|c|c|c|}
\hline Characteristics & Laser beam & $\begin{array}{l}\text { Electron } \\
\text { beam }\end{array}$ & Ultrasonic & Resistance & $\begin{array}{c}\text { Gas } \\
\text { tungsten } \\
\text { arc } \\
\end{array}$ & Friction & $\begin{array}{l}\text { Capacitive } \\
\text { discharge }\end{array}$ \\
\hline Weld quality & Excellent & Excellent & Excellent & Fair & Good & Good & Excellent \\
\hline Weld speed & High & High & High & Moderate & Moderate & Moderate & Very high \\
\hline $\begin{array}{l}\text { Heat imput into welded } \\
\text { part }\end{array}$ & Low & Low & Low & Moderate & Very high & Moderate & Low \\
\hline $\begin{array}{l}\text { Weld joint fitup } \\
\text { requirements }\end{array}$ & High & High & High & Low & Low & Moderate & High \\
\hline Weld penetration & High & High & Low & Low & Moderate & High & Low \\
\hline $\begin{array}{l}\text { Range of dissimilar } \\
\text { materials }\end{array}$ & Wide & Wide & Narrow & Narrow & Narrow & Wide & Wide \\
\hline $\begin{array}{c}\text { Range of part } \\
\text { geometries/sizes }\end{array}$ & Wide & Moderate & $\begin{array}{l}\text { Restricted } \\
\text { to lap joints }\end{array}$ & Wide & Wide & Narrow & Narrow \\
\hline Controllability & Very good & Good & Good & Fair & Fair & Moderate & Moderate \\
\hline Ease of automation & Excellent & Moderate & Good & Excellent & Fair & Good & Good \\
\hline Initial costs & High & High & High & Low & Low & Moderate & High \\
\hline $\begin{array}{l}\text { Operating/maintenance } \\
\text { costs }\end{array}$ & Moderate & High & High & Moderate & Low & Low & Moderate \\
\hline Tooling costs & High & Very high & High & Moderate & Moderate & Low & Very high \\
\hline
\end{tabular}

Table 1: Comparison of conventional and modern welding processes (Ready, 2001)

Laser welding is versatile and can provide excellent quality metallurgical joints with exceptional mechanical properties for a large variety of metal combinations if optimized thoroughly. The few weak points of the technique include the relatively high investment costs and the fact that demanding applications require tailor made laser systems. Nowadays, laser welding is getting more and more popular in the industry as the development of high-power diode and fiber lasers with very good beam properties is gaining steam. With these types of lasers highly automated laser joining systems operating at a very high speed with great precision and exceptional reproducibility can be built. Among other advantages, laser welding produces small heat affected zone (HAZ) that prevents metal distortion to occur and minimizes the chances of chemical reactions taking place during the bonding procedure, making the technique especially appealing for battery joining. On top of this, due to the high laser welding speeds attainable, only a small amount of intermetallic compounds (IMCs) are formed, that would cause brittleness and high porosity, if present in large quantities. To achieve optimal welding conditions however a thorough adjustment of process parameters is 
required because of the fact that there is a plethora of laser and material parameters that may affect the quality of the joint (Ready, 2001; Ferjutz et al., 1993; Dawes, 1992; Katayama, 2013).

- Laser welding is a versatile technique, providing excellent quality metallurgical joints for a large variety of metal combinations with exceptional mechanical properties. Therefore, it is an appealing approach even in aviation where extreme conditions are present and safe operation is of crucial importance.

- Stable good quality welding can be achieved up to $200 \mathrm{~mm} / \mathrm{s}$ scanning speed when using $360 \mathrm{~W}$ incident laser power focused onto $0.6 \mathrm{~mm}$ diameter spot for joining $0.5 \mathrm{~mm}$ thick DC01 steel sheets.

- Best reproducibility in electrical resistance is realized between 50 and $150 \mathrm{~mm} / \mathrm{s}$.

- The mechanical properties of the joints are the most stable between 50 and $100 \mathrm{~mm} / \mathrm{s}$.

- An optimal scanning speed range of 50-100 mm/s has been determined for the laser parameters given.

\section{EXPERIMENTAL}

In order to investigate the dependence of the electrical and mechanical properties of the laser welded battery joints on the process parameters a custom laser welding system was built allowing changing several laser and material process parameters. (Figure 2)

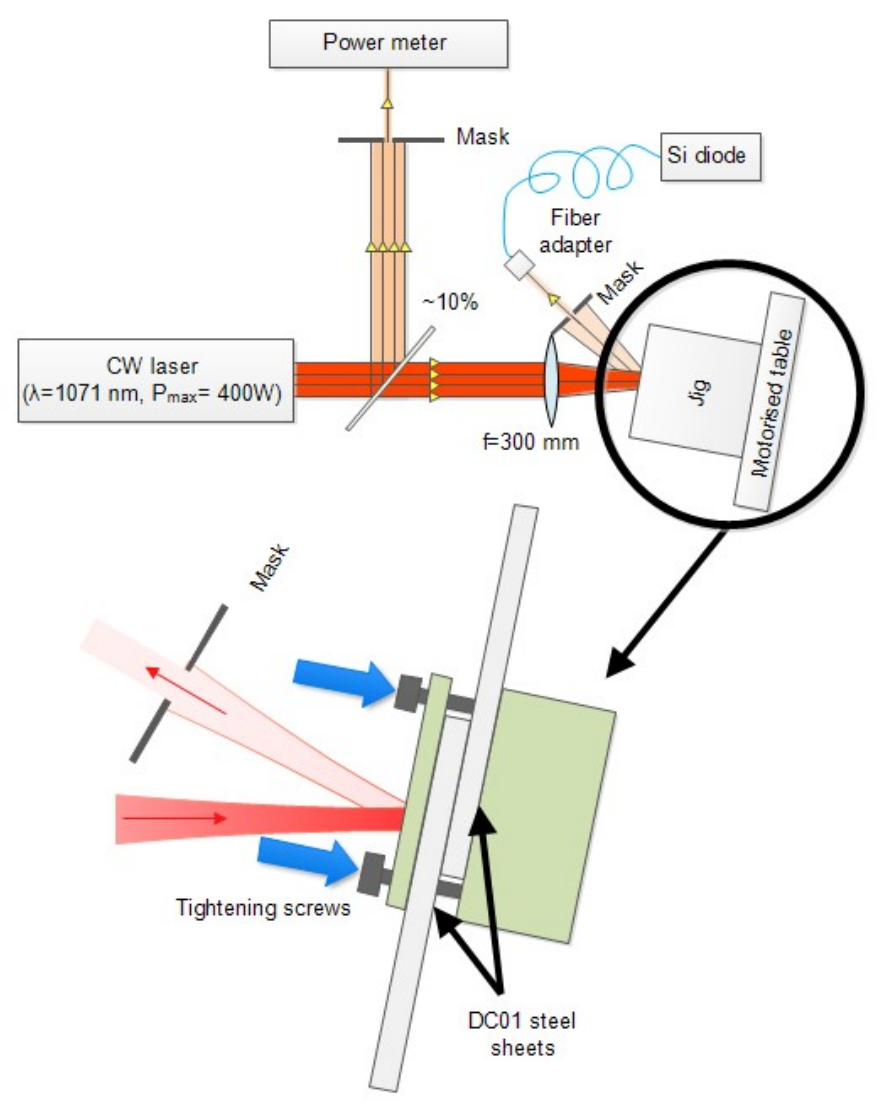

Figure 2: The schematic of the laser welding setup

A high-power single mode, Yb-doped continuous wave fiber laser (SPI SP-400C-0005: $1071 \mathrm{~nm}$ wavelength, $400 \mathrm{~W}$ maximum power, unpolarized, $\mathrm{M}^{2}=1.08$ ) was used as heat source. The laser beam was focused onto a $0.6 \mathrm{~mm}$ diameter spot on the surface of the upper sheet of a pair of $0.5 \mathrm{~mm}$ thick DC01 steel plates (that represents the batterybusbar interface) in a custom made jig at $10^{\circ}$ incidence angle using a $300 \mathrm{~mm}$ focal length lens. The jig was fixed onto a programmable high-speed table (Allen Bradley Ultra 3000) the speed of which could be changed in a relatively wide range, up to $500 \mathrm{~mm} / \mathrm{s}$. Using this setup, it was possible to produce autogenous laser welded joints in a lap joint 
configuration which is the closest model to battery joints. In-situ monitoring of the laser power was also possible with the setup.

DC01 type steel plates were chosen for the experiments based on the assumption that the base material used for the Li-ion cell casing production is similar in chemical composition and mechanical properties to low carbon non-alloy cold rolled steel. The main difference being that battery housings are usually coated with a thin layer of nickel or chrome to prevent corrosion.

The lap joint geometry was pivotal in our experiments to model both direct battery cap to bus bar joints and the more advanced stripe bonding processes. It is also considered to be the best and most commonly used configuration in laser assisted battery pack assembly (Shou, 2016).

In the standardized process used, the one and only process parameter systematically varied was the scanning speed, while every other system parameter (e.g.: laser power, incidence angle, pressure, temperature, gas atmosphere) remained fixed. The highest achievable laser power resulted in $360 \mathrm{~W}$ on the target surface. In order to ensure constant welding speeds a custom control system was built that generated a signal when the high-speed programmable table finished acceleration and reached the set speed. This signal was used as a trigger to start and end the laser light emission after a given distance. Using this method was pivotal to ensure that the welding speed remained the same for the entire length of the weld bead. The scanning speed was tuned from 5 to $250 \mathrm{~mm} / \mathrm{s}$ because this was the domain in which adequate joint formation was observable in our standardized model system with the process parameters mentioned.

Using the process described above, $8 \mathrm{~mm}$ long weld beads were made perpendicular to the two metal sheets as shown on the schematic in Figure 3 at different scanning speeds.

In order to characterize the strength of the joints, the measurement of the shear forces was the most convenient and expedient since the specimens were welded in a lap joint configuration. A mechanical tester (Tinius Olsen H5KT, is $0.1 \%$ measurement accuracy in the force range of our investigations) was used to determine maximum tensile-shear forces. In order to calculate the tensile shear strength values the joint areas were determined by analyzing optical microscope images of the weld seams after fracturing the joints. The digital 2D and 3D microscope images taken with an Olympus DSX510 microscope were analyzed in an image processing software (ImageJ). The joint areas were determined based on the contrast and texture differences on both sides of each metal sheets ( 4 values total). According to our observation the areas on the sides facing each other could be considered the same with less than $1 \%$ deviation. For the strength calculations the averages of these values were used.

Characterization of the electrical properties of the laser welded joints is not unified. The conductivity of the joints is not regularly investigated and therefore no standardized procedure is available. Research groups working on battery welding (e.g. V. Dimatteo et. al., 2019; U. Reisgen et. al., 2019; M. Jarwitz et. al., 2018; T. Solchenbach et. al., 2014) generally agree to adopt the measurement method introduced by Schmidt et al. and calculate a so-called $k$ factor that indicates how close is the bonding's resistance to the resistance of the base metal (Schmidt et al., 2012). Accordingly, we used a 4-point-probe method to determine the resistance of a fixed metal specimen length $(21 \mathrm{~mm}$ in our study due to constructional restraints) that contained the laser welded joint in an orientation perpendicular to the testing electrical current in the geometric center of it (Figure 3), using a desktop multimeter (Keithley 2401, with a measurement accuracy of $0.1 \%$ in the voltage range used for our experiments) and a power supply unit (TTi CPX200, with an accuracy of $1.1 \%$ for the maximum current used during the measurement process). 


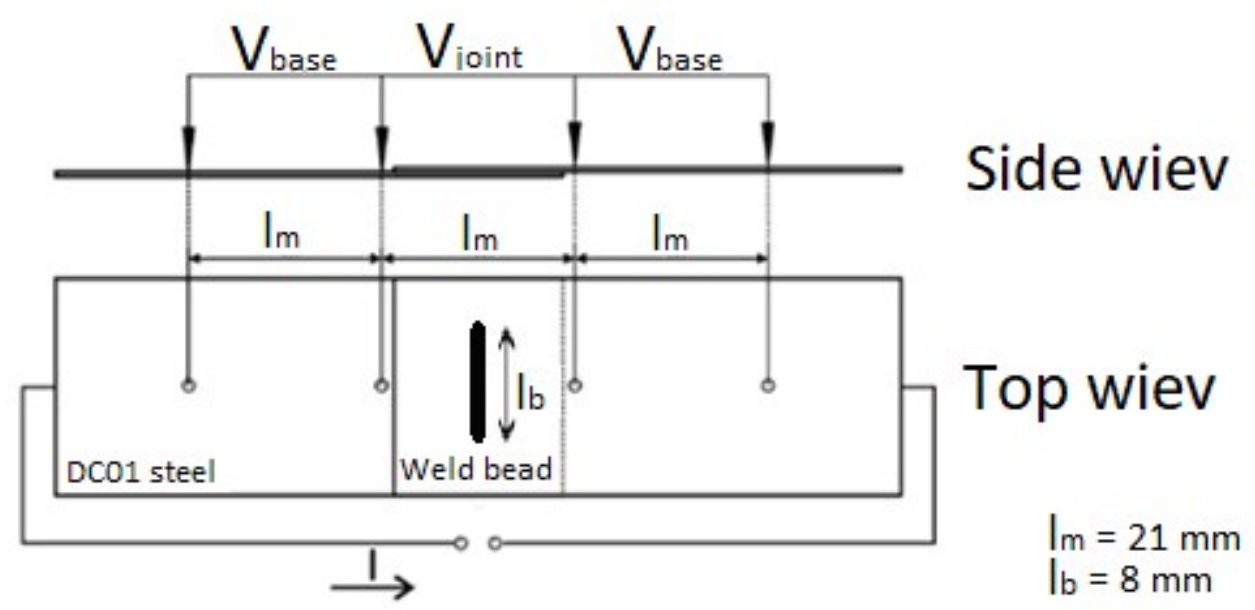

Figure 3: A laser welded specimen and the schematic arrangement of the probes during a 4 point probe resistance measurement

The values measured using this method can be considered equivalent to the $\mathrm{k}$ calculation method, since the joints were homogenous thus the $\mathrm{k}$ factor is merely different in a constant from our measured resistances.

Similar to $k$ factor determination these measurements do not represent the joint resistance directly as measuring the joint alone is impossible, the joint can only be measured together with its neighborhood that yields additional resistance (that is proportional to material properties and geometry). Nevertheless, the resistance values obtained can be used to pinpoint tendencies, when the bonds are standardized, i. e. the welded lengths are equal and the welded specimens have the same geometry).

\section{RESULTS AND DISCUSSION}

During the experiments the prime focus was on the investigation of the effect of the contact area on the electrical and mechanical characteristics of the joints. One possible way of varying the size of the contact areas can be achieved via the modification of the welding speed.

For assisting the discussion of the relationship between these two parameters, in Figure 4 the area of the joints is plotted against the welding speed. 


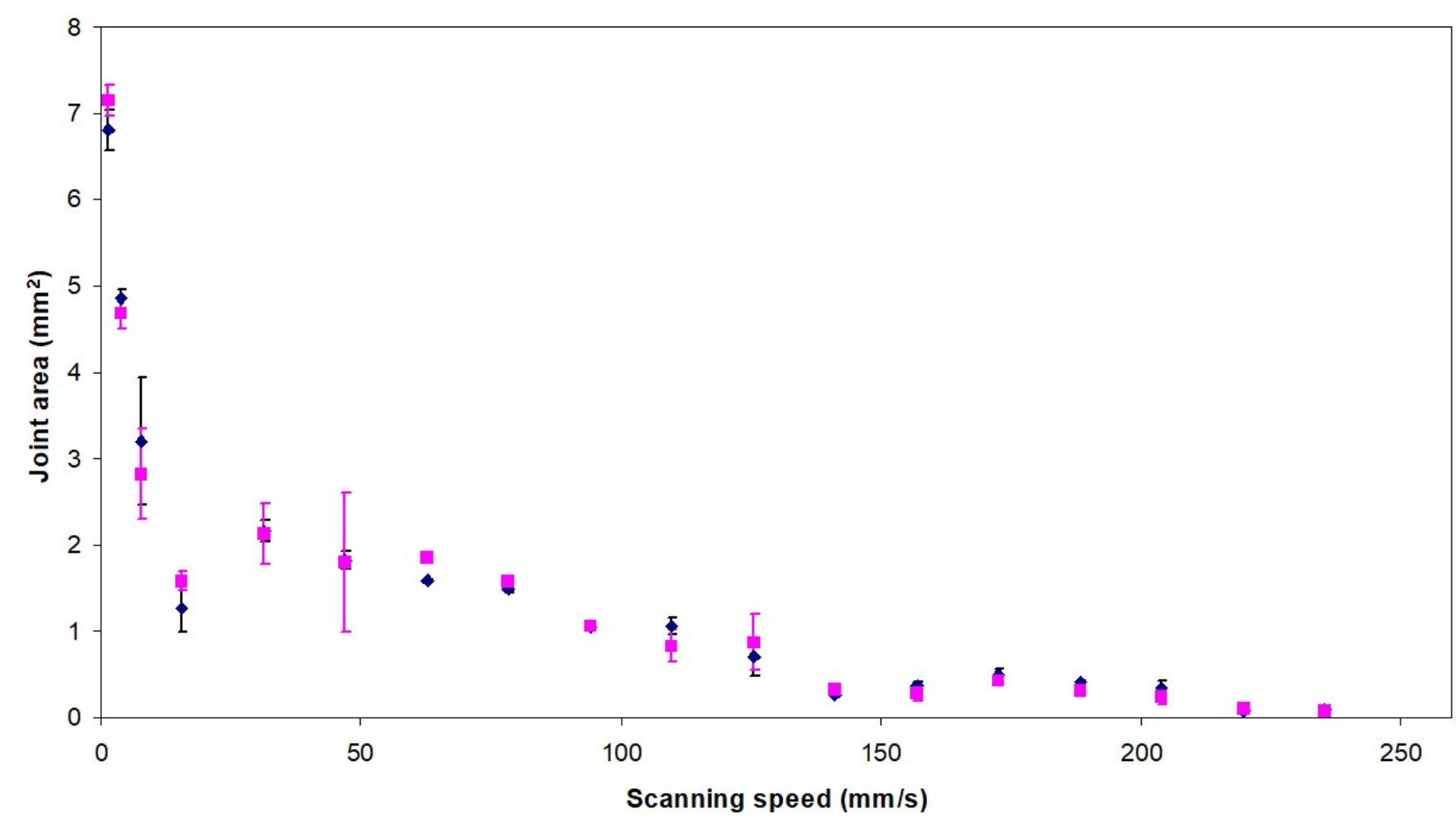

Figure 4: The contact areas as a function of scanning speed (1071 nm wavelength, $360 \mathrm{~W}$ power, unpolarized beam, $0.6 \mathrm{~mm}$ diameter spot size, $0.5 \mathrm{~mm}$ thick DC01 steel sheets)

The figure shows the results of three independent measurement series. The joint area values plotted in this graph were measured on the facing surfaces of the two metal sheets to be welded by optical microscopy (Olympus DSX510). The diamond symbols represent the area on the surface closer to the incident laser beam while the square symbols indicate the areas on the bottom counterpart. It can be noted that these two area values differ only slightly (less then $1 \%)$ from one another, proving an efficient energy transfer between the upper and lower sheets. Therefore, in the following discussion and for later tensile shear strength calculations the contact areas were considered as the average of these two values.

Up to approximately $25 \mathrm{~mm} / \mathrm{s}$ the size of the contact area decreases steeply with increasing welding speed. When exceeding this welding speed threshold, the previously observed tendency continues while the rate of the decay decreases significantly. At around $140 \mathrm{~mm} / \mathrm{s}$ laser scanning speed, another breakpoint can be observed, after which the contact area changes only slightly as it approaches zero.

In Figure 5 the dependence of the electrical resistance is presented as a function of contact area. Both resistance and the contact area values are averages of three measurements. 


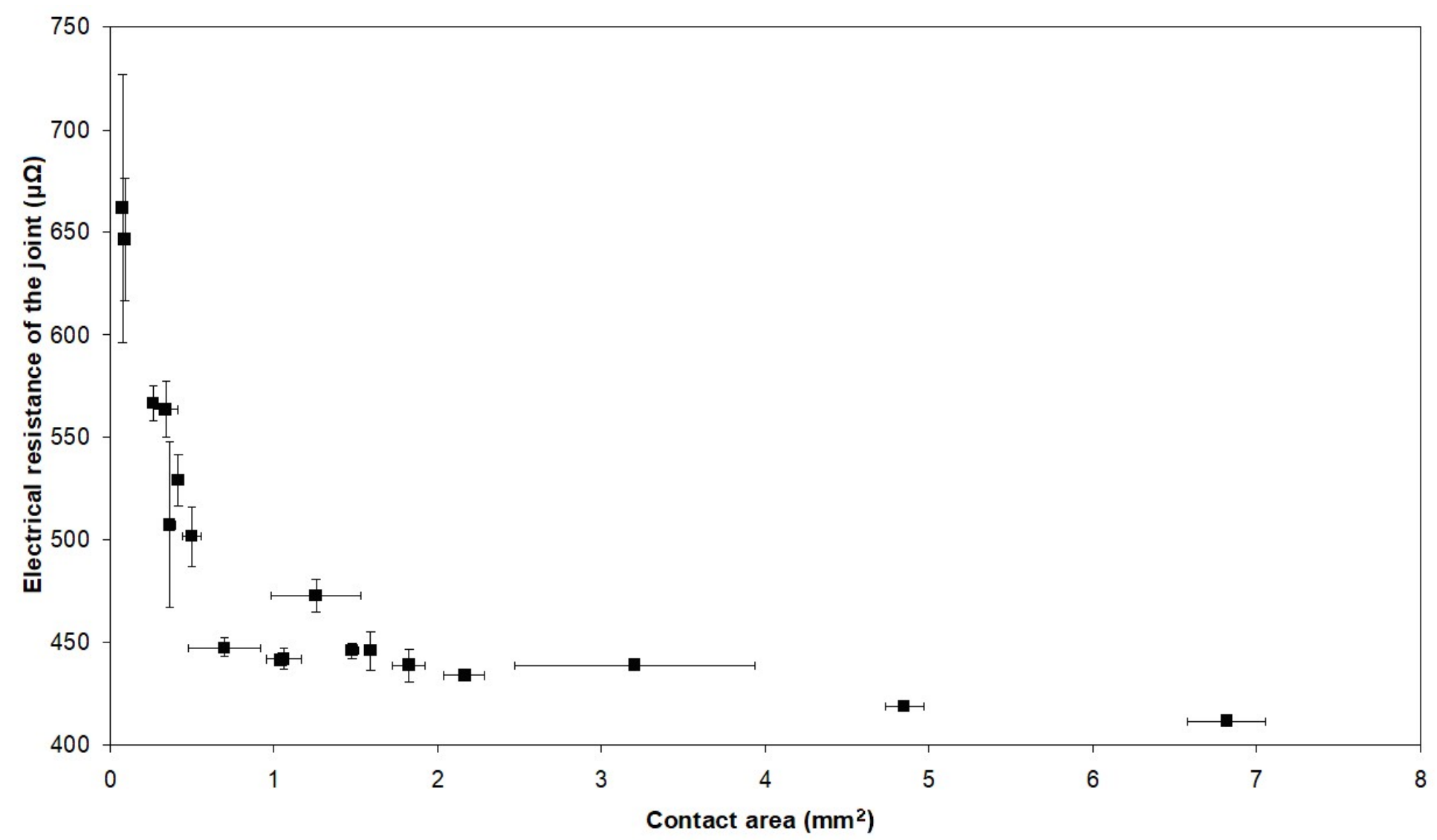

Figure 5: Electrical resistance versus contact area $(1071 \mathrm{~nm}$ wavelength, $360 \mathrm{~W}$ power, unpolarized beam, $0.6 \mathrm{~mm}$ diameter spot size, $0.5 \mathrm{~mm}$ thick DC01 steel sheets)

When the contact area is relatively small the electrical resistance of the laser welded specimens is rather high and the reproducibility is poor. The electrical resistance falls sharply with increasing contact area in the $0.07-0.5 \mathrm{~mm}^{2}$ range until reaching a threshold at about $0.5 \mathrm{~mm}^{2}$. Exceeding this threshold, the electrical resistance of the joints continues to decrease further with increasing contact areas but at greatly reduced rate. The resistance of the laser welded joints converges to the base resistance of the unwelded material $(400.1 \pm 4.8 \mu \Omega)$.

The measured maximum tensile shear force values are plotted against the contact area in Figure 6. 


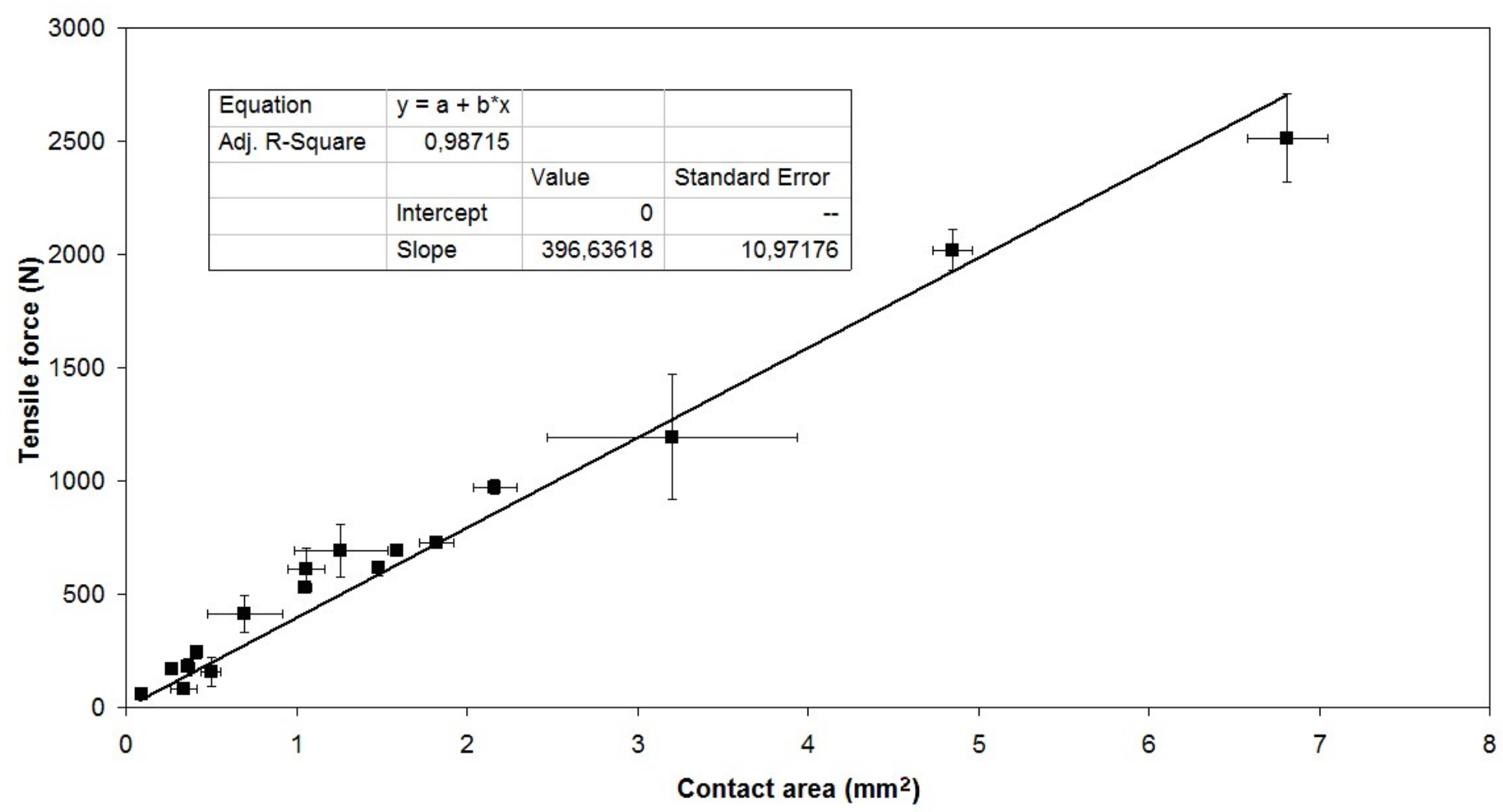

Figure 6: Maximum tensile shear force as a function of contact area and a zero-intercept linear fit (1071 nm wavelength, $360 \mathrm{~W}$ power, unpolarized beam, $0.6 \mathrm{~mm}$ diameter spot size, $0.5 \mathrm{~mm}$ thick DC01 steel sheets)

Note that in this representation the maximum shear force is a linear function of the contact area. What is more, the slope of the fitted straight line is $396.64 \pm 10.97 \mathrm{MPa}$ that corresponds well to the nominal tensile strength of the DC01 steel (about $400 \mathrm{MPa}$ according to the measurements of the supplier).

All in all, when plotting the electrical and mechanical properties of the welds as a function of the contact area, results show that a threshold contact area value has to be reached in order to gain sufficient reproducibility for electrical properties. Increasing the contact area further does not yield significant decrease in joint resistance or noticeably increased reproducibility. The results also show that the tensile shear strength of the laser welded specimens in general can be sufficiently described by the size of the contact area as the maximum shear force that the joint can withstand is a linear function of the joint area and the strength is solely limited by the bulk mechanical properties of the metal.

When considering the electrical and mechanical properties jointly, having a contact area of around $1 \mathrm{~mm}^{2}$ is optimal for battery welding applications, with the restriction that having too large contact areas result in working at low welding speeds that increases heat load and thus the chance of possible target damage.

In order to assist the process optimization, i.e. to find the optimum welding speed interval in which both the electrical and mechanical behavior of the weld is sufficiently stable (average $\pm 10 \%$ is considered good for engineering applications), the measurement results were replotted as a function of the laser scanning speed.

In Figure 7 the electrical resistance of the specimens is plotted against the scanning speed. Every point represents the average of three independent measurement series. The vertical black bars represent the individual errors of each point $(97 \%$ confidence level) calculated from the standard deviations. 


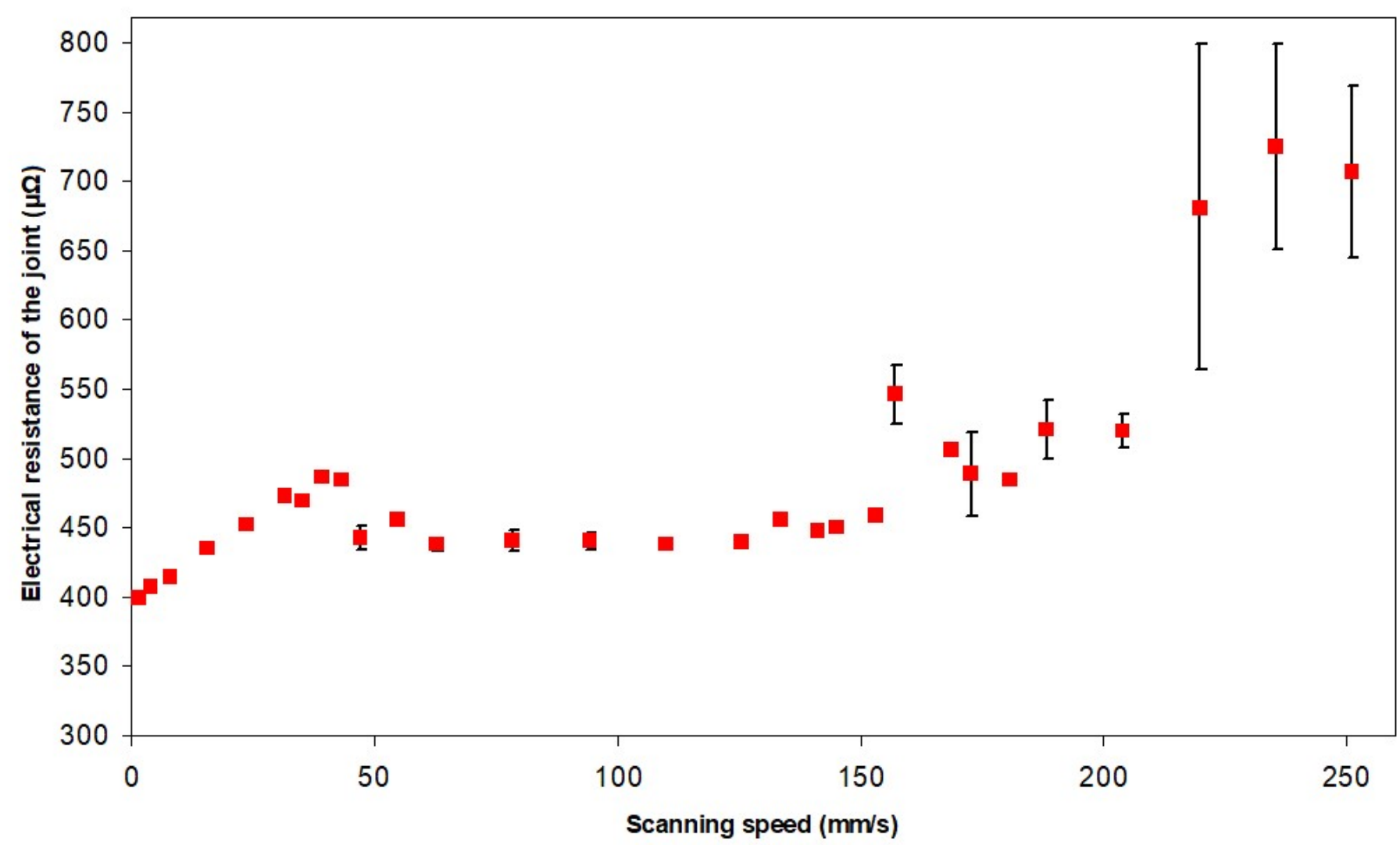

Figure 7. Scanning speed dependence of the electrical resistance of the laser welded joints (1071 nm wavelength, $360 \mathrm{~W}$ power, unpolarized beam, $0.6 \mathrm{~mm}$ diameter spot size, $0.5 \mathrm{~mm}$ thick DC01 steel sheets)

As a general trend the electrical resistance of the joints rises steadily with increasing scanning speed.

Welding at very low scanning speeds (below $25 \mathrm{~mm} / \mathrm{s}$ ) result in large heat affected zone (HAZ) on the target surface and in most cases damages it: drilled holes or cuts may also be formed, thus using such speeds should be avoided for battery welding applications. The visual appearance of the weld beads made at these relatively low speeds is highly irregular and many spatter formations can be observed along it. As a side note, the electrical resistance of the joints manufactured in this slow scanning speed domain is the lowest and accompanied by appealingly high reproducibility.

From about $50 \mathrm{~mm} / \mathrm{s}$ up to $150 \mathrm{~mm} / \mathrm{s}$ welding speeds, the electrical resistance stays at a relatively low, constant level (at around $438.8 \pm 3.4 \mu \Omega$ ) with excellent reproducibility (less than $1 \%$ error). The area of the heat affected zone for these speeds is considerably smaller, than it was in the first (slow speed) regime. The weld bead becomes more regular and visually appealing, and the target surface does not show any signs of visible weld defects or damage.

At the highest welding speeds studied, i.e. above $200 \mathrm{~mm} / \mathrm{s}$, the electrical resistance values increase considerably, while the reproducibility falls sharply, rendering this region unappealing for battery joining operations. Working at these weld speeds is crucial and essential in practice as at great speeds the productivity of the welding process increases and the least amount of heat is transmitted into the target surface, thus the base metal and potential chemicals that are present inside a Li-ion battery cell suffer minimal thermal damage.

In order to put the laser welded results into perspective, the above measurement results were also compared to both the electrical resistance of unwelded DC01 metal sheets, obtained in identical geometry, and to the resistance of specimens that were welded using a conventional industrial spot-welding machine. The results of the former measurements show that the base DC01 metal sheets (these specimens had exactly the same geometry and material properties as the welded specimens) have an average electrical resistance of $400.1 \pm 4.8 \mu \Omega$ that is slightly lower than those of the laser welded joints, exhibiting the lowest resistance. The spot welded joints prepared with set process 
parameters (that were considered optimal for this metal combination, thickness and geometry by welding experts) by the conventional welding setup have a rather low reproducibility, but overall results in $456.3 \pm 16.2 \mu \Omega$ resistance that shows that the average is about $7 \%$ higher than the resistance values achieved in the optimal laser welding speed parameter window.

Analogue to the electrical investigations the mechanical properties of the weld were also replotted. The results are shown in Figures 8 and 9 for the tensile shear tests.

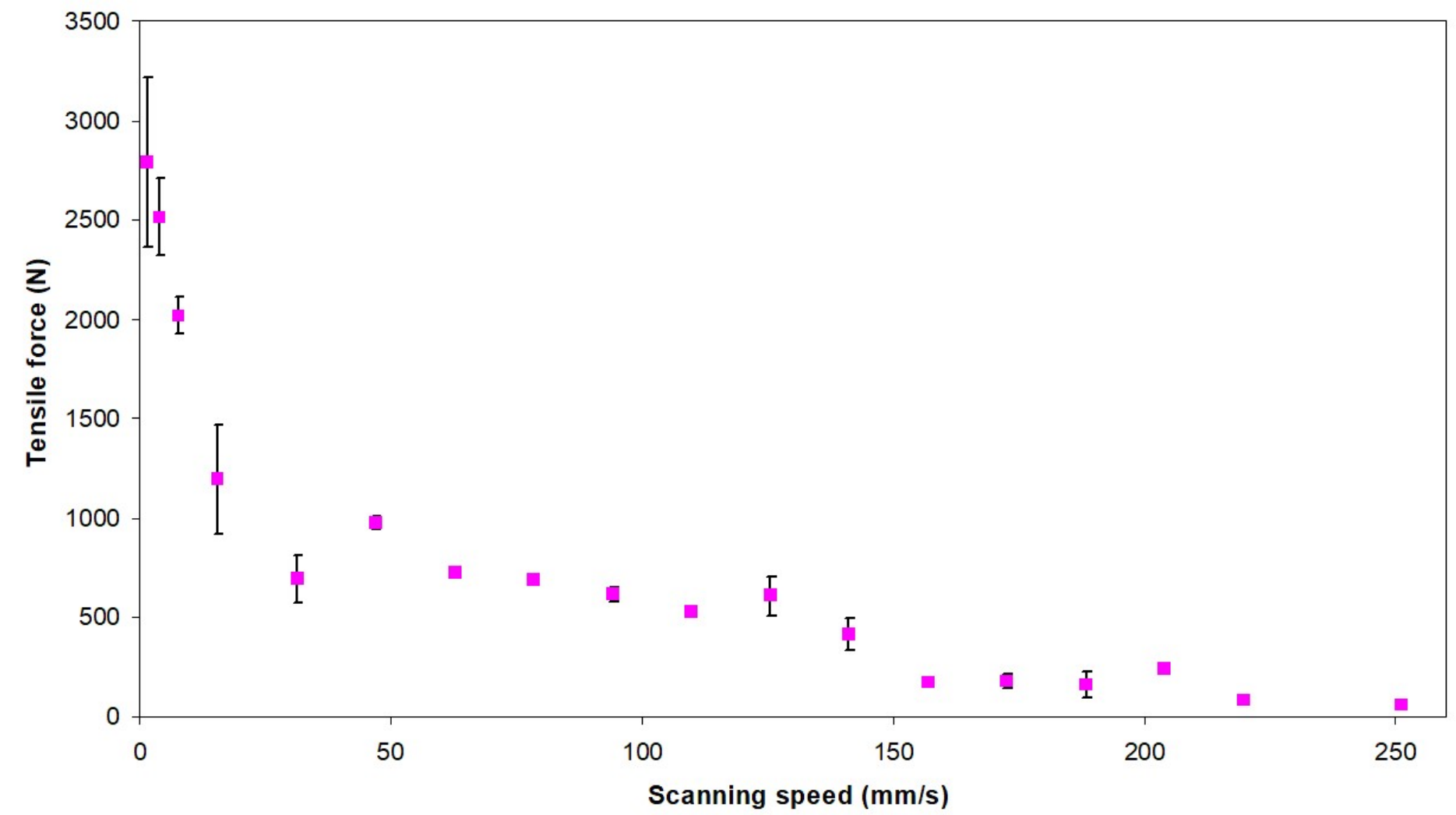

Figure 8. Scanning speed dependence of the maximum tensile shear force of the laser welded joints. $(1071 \mathrm{~nm}$ wavelength, $360 \mathrm{~W}$ power, unpolarized beam, $0.6 \mathrm{~mm}$ diameter spot size, $0.5 \mathrm{~mm}$ thick DC01 steel sheets)

The laser scanning speed dependence of the maximum tensile shear force looks almost identical to the contact area plot (cf. Figure 4). This is in line with the conclusions obtained by the contact area representation, namely that the maximum tensile force is a linear function of the contact areas and the mechanical strength of the joints are not dependent on the laser scanning speed. 


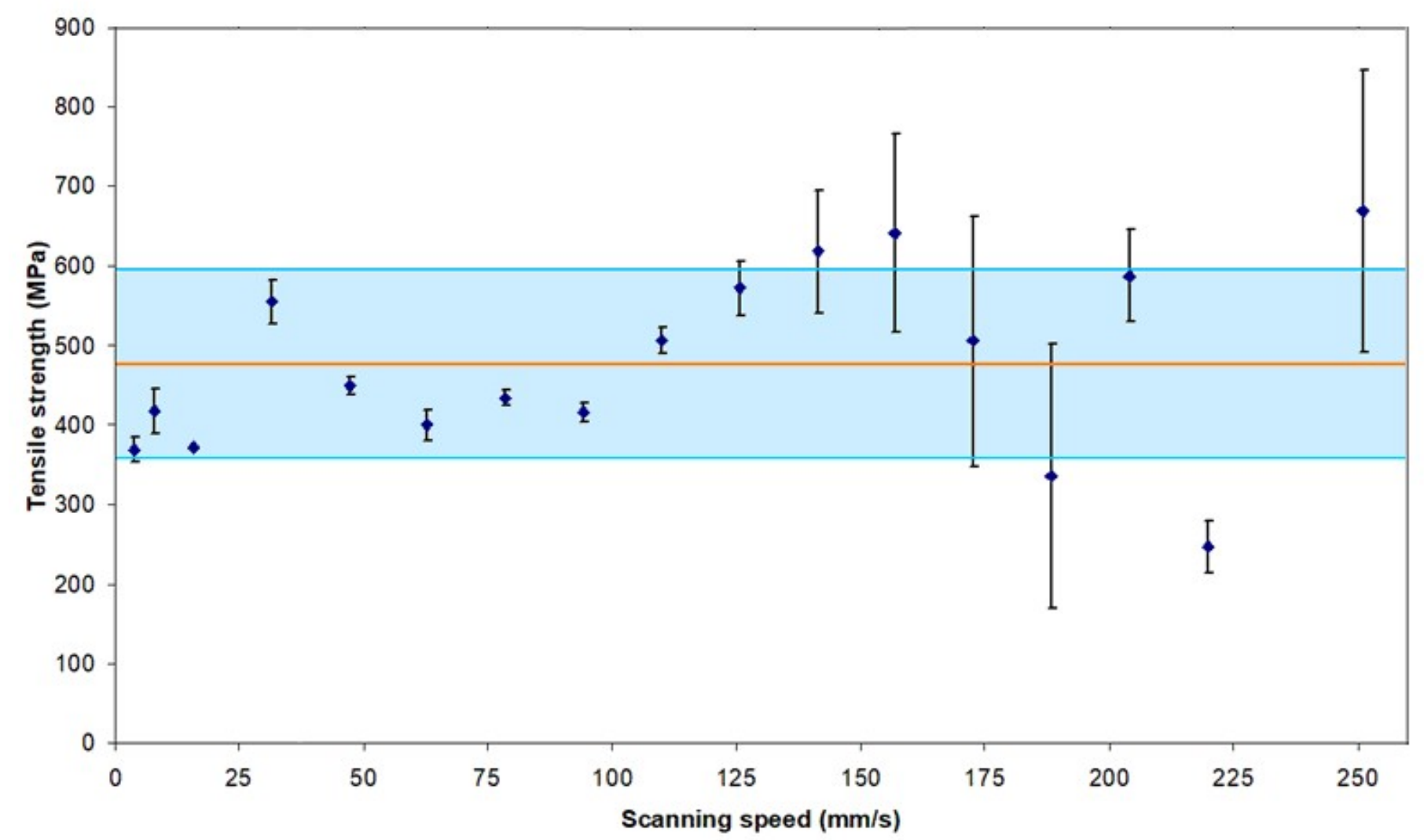

Figure 9. Scanning speed dependence of the tensile shear strength of the laser welded joints. (the horizontal light bar represents the $97 \%$ confidence interval) (1071 nm wavelength, $360 \mathrm{~W}$ power, unpolarized beam, $0.6 \mathrm{~mm}$ diameter spot size, $0.5 \mathrm{~mm}$ thick DC01 steel sheets)

As a consequence, in terms of tensile-shear strength no significant tendencies could be observed in the welding speed range investigated. The measured tensile shear strength of the specimens scatter around an average value of about $480 \mathrm{MPa}$ within a relatively wide domain, i.e., from 300 to $700 \mathrm{MPa}$.

Avoiding low welding speeds (below $25 \mathrm{~mm} / \mathrm{s}$ ), similar to the case of electrical properties, however is beneficial both for gaining superior mechanical properties, reproducibility and to preserve target integrity. It can be observed that the samples made with welding speeds varying from $50 \mathrm{~mm} / \mathrm{s}$ to $100 \mathrm{~mm} / \mathrm{s}$ speeds show little variation in mechanical strength with outstanding reproducibility and moderate overall mechanical strength. The span of this welding speed interval is considerably smaller than in the case of electrical resistance but is still well within the practical $\pm 10 \%$ range. When approaching the high speed domain, the increase in tensile shear strength is accompanied by gradually worsening reproducibility. Similar to the electrical considerations, working at high welding speeds is enticing but prove to be non expedient for battery joining applications in terms of consistent mechanical properties.

The tensile shear strength values obtained here is as well compare to both the nominal tensile shear strength of DC01 steel and to the strength of specimens that were welded using conventional spot-welding machine. With the base DC01 metal having an average nominal tensile strength of about $400 \mathrm{MPa}$ it can be said that in most cases the laser welded joints can be considered exceptional in mechanical quality. When comparing the mechanical properties of the laser and conventional spot welded specimens, the latter having a tensile shear strength of $369.8 \pm 66.2 \mathrm{MPa}$, it can be concluded that the laser welded samples exhibit about $20 \%$ higher tensile shear strength and far better reproducibility.

In order to optimize the laser welding process for battery joining application a welding speed parameter window has to be defined where electrical and mechanical properties jointly have to fulfill the formerly mentioned engineering conditions. According to this definition the optimal laser scanning speed lies from $50 \mathrm{~mm} / \mathrm{s}$ to $100 \mathrm{~mm} / \mathrm{s}$. In this 
relatively wide speed window outstanding reproducibility is accompanied by a fairly constant level of mechanical and electrical properties.

\section{CONCLUSIONS}

In this paper the effect of the scanning speed of the processing laser beam on the quality of the weld seam and thereby the electrical and mechanical properties of the laser welded joints were discussed considering the stringent requirements of the application of the technique in aviation. The results are represented and discussed in terms of the contact area and the laser scanning speed.

It is concluded that a minimal joint contact area of $0.5 \mathrm{~mm}^{2}$ must be reached in order to produce joints of good mechanical and electrical properties with acceptable level of reproducibility. Beyond this threshold both the electrical and mechanical properties improve (the former only slightly), but the productivity decreases and the heat load on the target surface increases. The strength of the laser welded joint remains constant in a broad window of welding speed in the DC01 steel model system.

Based upon our experimental results for a battery welding model system consisting of $0.5 \mathrm{~mm}$ thick DC01 steel specimens situated in lap joint geometry as test material processed by a continuous wave laser of $360 \mathrm{~W}$ power emitting at $1071 \mathrm{~nm}$ wavelength, focused onto a $0.6 \mathrm{~mm}$ diameter spot on the sample surface, the following conclusions can be made in terms of battery welding speed optimization:

- When considering electrical properties alone, the $50-150 \mathrm{~mm} / \mathrm{s}$ speed range is the most appealing parameter window for battery welding applications, as joints with an outstandingly low electrical resistance and excellent reproducibility could be achieved in this relatively wide scanning speed domain.

- In terms of solely mechanical properties, the $50-100 \mathrm{~mm} / \mathrm{s}$ interval provides the optimal laser scanning speed window. The specimens made in this scanning speed range exhibit moderate and constant mechanical properties with fair reproducibility.

- When looking at the electrical and mechanical properties jointly and taking the stringent safety requirements of the aviatic applications into account, it can be concluded that according to the results the $50-100 \mathrm{~mm} / \mathrm{s}$ welding speed range provides the optimal laser welded joints for the investigated DC01 model system.

\section{ACKNOWLEDGEMENT}

\section{REFERENCES}

S. Ekici, I. Orhan, T. H. Karakoc, A. Hepbasli (2020). 'Milestone of Greening the Flight Path: Alternative Fuels.', Sustainable Aviation, pp.243-253

Ö. Altuntaş, Y. Şöhret T. H. Karakoc, 'Fundamentals in Sustainability' in Sustainable Aviation, T. Hikmet Karakoc, C. Ozgur Colpan, Onder Altuntas and Yasin Sohret Eds., Springer, (2019)

I. Gál, I. Jankovics, Gy. Bicsák, Á. Veress, J. Rohács, D. Rohács (2017) 'Conceptual design of a small 4-seater aircraft with hybrid propulsion system', IFFK 2017, pp. 143-150

R. Cipin, J. Kadlec, B. Klima, P. Hutak (2014) 'Battery System for the Airplane VUT 051 RAY', ECS Transactions, Vol. 48 (1), pp. 217-222

S. S. Lee, T. H. Kim, S. J. Hu, W. W. Cai, J. A. Abell (2010) 'Joining Technologies For Automotive Lithium-Ion Battery Manufacturing - A Review’, ASME Proceedings, Paper No. MSEC2010-34168, pp. 541-549

J. F. Ready (2001) LIA Handbook of Laser Materials Processing, Magnolia Publishing

K. Ferjutz, J. R. Davis (1993) ASM Handbook Vol. 6 Welding, Brazing and Soldering, ASM International 
M. J. Brand, P. A. Schmidt, M. F. Zaeh, A. Jossen (2015) 'Welding techniques for battery cells and resulting electrical contact resistances' Journal of Energy Storage, Vol. 1, pp. 7-14

B. Mehlmanna, E. Gehlena, A. Olowinskya, A. Gillnera (2014) 'Laser micro welding for ribbon bonding', Physics Procedia, Vol. 56, pp. 776-781

C. Dawes (1992) Laser Welding - A Practical Guide, Abington Publishing

S. Katayama (2013) Handbook of laser welding technologies, Woodhead Publishing

P. A. Schmidt, P. Schmitz, M. F. Zaeh (2016) 'Laser beam welding of electrical contacts for the application in stationary energy', Journal of Laser Applications. Vol. 28, 022423

M. C. Zhou (2016) Advances in battery manufacturing, services, and management systems, IEEE Press

V. Dimatteo, A. Ascari, A. Fortunato (2019) 'Continuous laser welding with spatial beam oscillation of dissimilar thin sheet materials ( $\mathrm{Al}-\mathrm{Cu}$ and $\mathrm{Cu}-\mathrm{Al})$ : Process optimization and characterization', Journal of Manufacturing Processes, Vol. 44, pp. 158-165

U. Reisgen, S. Olschok, N. Holtum (2019) 'Influencing the electrical properties of laser beam vacuum-welded Cu-Al mixed joints', Journal of Laser Applications, Vol. 31, 022406

M. Jarwitz, F. Fetzer, R. Weber, T. Graf (2018) 'Weld Seam Geometry and Electrical Resistance of Laser-Welded, Aluminum-Copper Dissimilar Joints Produced with Spatial Beam Oscillation', Metals - Open Access Metallurgy Journal, Vol. 8(7), 510

T. Solchenbacha, P. Plapper, W. Cai (2014) 'Electrical performance of laser braze-welded aluminum-copper interconnects', Journal of Manufacturing Processes, Vol. 16, pp. 183-189

P. A. Schmidt, M. Schweier, M. F. Zaeh (2012) 'Joining of lithium-ion batteries using laser beam welding: electrical losses of welded aluminum and copper joints', ICALEO 2012, Paper \#805 